\title{
Prognostic nomograms for predicting cause-specific survival and overall survival of stage I-III colon cancer patients: a large population-based study
}

Zheng Zhou ${ }^{1,2 \dagger}$, Shaobo Mo ${ }^{1,2 \dagger}$, Weixing Dai ${ }^{1,2}$, Wenqiang Xiang ${ }^{1,2}$, Lingyu Han ${ }^{1,2}$, Qingguo Li, ${ }^{1,2}$, Renjie Wang ${ }^{1,2}$, Lu Liu ${ }^{4}$, Long Zhang ${ }^{1,3^{*}}$, Sanjun Cai ${ }^{1,2^{*}}$ and Guoxiang Cai ${ }^{1,2^{*}}$

\begin{abstract}
Background: The purpose of this study was to build functional nomograms based on significant clinicopathological features to predict cause-specific survival (CSS) and overall survival (OS) in patients with stage I-III colon cancer.

Methods: Data on patients diagnosed with stage I-III colon cancer between 2010 and 2015 were downloaded from the Surveillance, Epidemiology, and End Results (SEER) database. Univariate and multivariate Cox analyses were used to identify independent prognostic factors, which were used to construct nomograms to predict the probabilities of CSS and OS. The performance of the nomogram was assessed by C-indexes, receiver operating characteristic (ROC) curves and calibration curves. Decision curve analysis (DCA) was used to compare clinical usage between the nomogram and the tumor-node-metastasis (TNM) staging system.

Results: Based on the univariate and multivariate analyses, features that correlated with survival outcomes were used to establish nomograms for CSS and OS prediction. The nomograms showed favorable sensitivity at predicting 1-, 3-, and 5-year CSS and OS, with a C-index of 0.78 (95\% confidence interval (Cl) $0.77-0.80$ ) for CSS and 0.74 (95\% Cl $0.73-0.75)$ for OS. Calibration curves and ROC curves revealed excellent predictive accuracy. The clinically and statistically significant prognostic performance of the nomogram generated with the entire group of patients and risk scores was validated by a stratified analysis. DCA showed that the nomograms were more clinically useful than TNM stage.

Conclusion: Novel nomograms based on significant clinicopathological characteristics were developed and can be used as a tool for clinicians to predict CSS and OS in stage I-III colon cancer patients. These models could help facilitate a personalized postoperative evaluation.
\end{abstract}

Keywords: Colon cancer, Nomogram, Cause-specific survival, Overall survival, Decision curve analysis

*Correspondence: longzhangcrc@yeah.net; caisanjun_sh@163.com; gxcaifuscc@163.com

${ }^{\dagger}$ Zheng Zhou and Shaobo Mo contributed equally to this work

${ }^{1}$ Department of Colorectal Surgery, Fudan University Shanghai Cancer Center, 270 Dong'an Road, Shanghai 200032, China

Full list of author information is available at the end of the article

\section{Background}

Colon cancer accounts for more than 1632 deaths per day and has a morality rate of approximately 19.1/100,000, ranking fourth in China and making it the most common malignant digestive tumor [1]. The incidence of colon cancer and patient overall survival (OS) have continued to increase over the past 3 decades worldwide [2]. Patients with colon cancer had a 5-year OS rate of $65.2 \%$,

(c) The Author(s) 2019. This article is licensed under a Creative Commons Attribution 4.0 International License, which permits use, sharing, adaptation, distribution and reproduction in any medium or format, as long as you give appropriate credit to the original author(s) and the source, provide a link to the Creative Commons licence, and indicate if changes were made. The images or other third party material in this article are included in the article's Creative Commons licence, unless indicated otherwise in a credit line to the material. If material is not included in the article's Creative Commons licence and your intended use is not permitted by statutory regulation or exceeds the permitted use, you will need to obtain permission directly from the copyright holder. To view a copy of this licence, visit http://creativecommons.org/licenses/by/4.0/. The Creative Commons Public Domain Dedication waiver (http//creativecommons.org/publicdomain/zero/1.0/) applies to the data made available in this article, unless otherwise stated in a credit line to the data. 
which made colon cancer a serious problem for public health.

The prognosis of colon cancer is associated with the American Joint Commission on Cancer/International Union against Cancer (AJCC/UICC) tumor-nodemetastasis (TNM) staging system. According to stages defined by the TNM system, the 5-year stage-specific survival rates are $93.2 \%$ for stage I, $82.5 \%$ for stage II, and $59.5 \%$ for stage III [3]. Nonetheless, patients with stage I-III colon cancer usually have an obviously divergent prognosis because of discrepant genetic and epigenetic backgrounds, even though some colon cancer patients are in the same AJCC stage. Compared with patients with stage IIIa colon cancer, whose 5-year survival rate is $83.4 \%$, patients with stage IIb colon cancer, whose 5 -year survival rate is $72.2 \%$, experience severe prognostic events similar to patients with stage IIIb colon cancer, whose 5-year survival rate is $64.1 \%$ [4]. Although the TNM staging system is most widely used for prognosis assessment and medical treatments in colon cancer patients, excessive hidden defects still limit its practical application.

Some studies have described that clinicopathological features such as tumor size, the carcinoembryonic antigen (CEA) level, adjuvant chemotherapy, and the $\log$ odds of metastatic lymph nodes (LODDS) may also influence colon cancer patients' survival outcomes $[5,6]$. In addition to clinicopathological features, various nonbiological factors were proposed to be included in the patient's clinical assessment for malignant tumor therapy. For instance, marital status is a significant factor in clinical resolution. Socioeconomic status and insurance status are also important when selecting a treatment strategy. Multiple factors are needed to account for the wide range of variability observed in individual patients. Ignoring these significant prognostic parameters may reduce the accuracy of survival predictions. Thus, a comprehensive prognostic judgment system including clinicopathological and demographic factors is required in clinical practice.

In fact, various prognostic analysis methods have been applied to clinical applications. For instance, microsatellite instability (MSI) or mismatch repair deficiency (dMMR) status is considered the most important biomarker in colon cancer patients [7, 8]. Chromosomal instability (CIN) and CpG island methylator phenotype (CIMP) are also widely accepted as biomarkers for metastasis risk and prognostic analysis [9]. In addition, certain genes and molecules, such as the KRAS gene, the APC gene, the p53 gene, CD44, CD133, and MEK, have been found to be indicators for judging the prognosis of colon cancer patients [10-12]. However, these methods of detection and judgment not only sometimes result in trauma to the patient but also have considerable economic costs. As a convenient and saving graphical interface of a statistical prediction model, nomograms in which various significant variables are combined to predict a specific endpoint have been built by scientists to meet this demand. By integrating these clinical and pathological features, a nomogram simplifies the complicated computational model into a single numerical estimation probability, such as death or disease recurrence, which is tailored to the individual condition. Therefore, a nomogram might be used as a dependable instrument for predicting patients' survival outcomes and supporting decisions with regard to surgery, surveillance, and adjuvant treatments. Recently, some researchers have reported that the nomogram scoring system has an exceptional capability in predicting prognosis $[13,14]$. However, most nomograms used to predict the prognosis of patients with colon cancer, of which the sample size used for development was limited, required a combination of molecular biology tests, which increased the economic burden, time and cost for the patient. This research aimed to develop nomograms that require only clinical features combined with the patient's socioeconomic status, which is easy to obtain.

The Surveillance, Epidemiology, and End Results (SEER) program provides a profusion of integral information for different cancers from 20 cancer registries that cover $\sim 28 \%$ of the population. Based on the SEER database, researchers have conducted several studies on the prognosis of cancer [15]. In the present research, information on stage I-III colon cancer was collected from the SEER database to build a nomogram that was intuitive and convenient for predicting the prognosis of colon cancer patients.

\section{Methods}

\section{Patients selection}

In this study, a total of 167,333 patients with colon cancer were acquired from the SEER database. The detailed workflow for patient selection is shown in Fig. 1. All colon cancer patients treated with radical surgery between January 1, 2010 and December 31, 2015, were assessed for inclusion in the retrospective analysis. Patients were excluded if non-colon cancer was stated in the pathology report, if they were diagnosed with TNM stage IV or an unknown stage cancer and if they suffered from 2 or more malignant tumors. Eighteen variables were extracted from the SEER program in this study, including race, carcinoembryonic antigen (CEA) level, age, year of diagnosis, sex, adjuvant chemotherapy, histological type, grade, tumor size, number of lymph nodes harvested (LNH), regional nodes positive, LODDS stage, marital status, tumor site, tumor deposit, $\mathrm{T}$ stage, $\mathrm{N}$ stage, 
Patients with colon caner in SEER database from 2010 to $2015(\mathrm{n}=167333)$

Exclusion $(\mathrm{n}=90051)$

1. Non-colon cancer $(n=36367)$

2. TNM stage IV and unknown $(n=22215)$

3. Patients with 2 or more malignant tumors $(n=31469)$

Patients with stage I-III colon caner $(\mathrm{n}=77282)$

Exclusion $(\mathrm{n}=42850)$

1. Race unknown $(\mathrm{n}=534)$

2. Grade unknown $(n=2908)$

3. T stage missing $(n=269)$

4. N stage missing $(n=203)$

5. LNH missing $(\mathrm{n}=38)$
6. Therapy method unknown $(\mathrm{n}=2424)$

7. CEA unknown $(\mathrm{n}=30810)$

8. No surgery $(n=260)$

9. Tumor deposits unknown $(\mathrm{n}=3500)$

10. Marriage unknown $(n=1797)$

11. End points missing $(\mathrm{n}=107)$

Eligible patients with stage I-III colon cancer $(n=34432)$

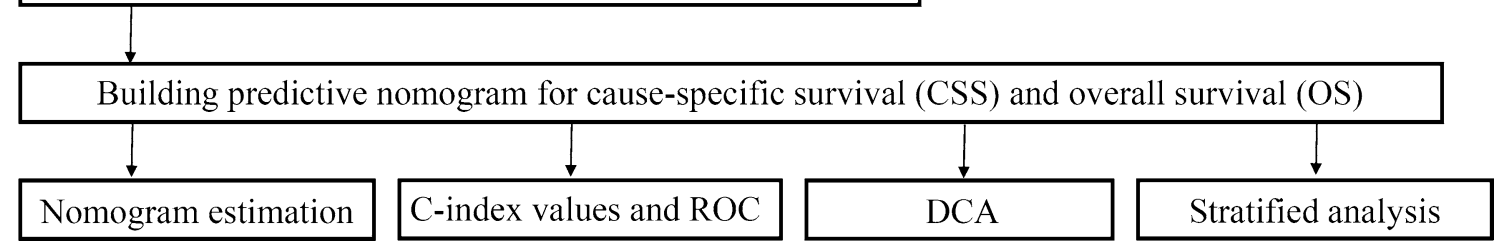

Fig. 1 The workflow of establishment of nomograms to predict cause-specific survival and overall survival of patients with stage I-III colon cancer

and TNM stage. Patients whose races were recorded as Native American, Asian, Pacific Islander and unknown in the SEER database were assigned to the "other" race category for analysis. Patients without any of these 18 variables were excluded. Patient survival was measured as cause-specific survival (CSS) and OS [16]. Finally, data on 34,432 patients diagnosed with stage I-III colon cancer between 2010 and 2015 were obtained from the SEER database.

\section{Construction and validation of the nomogram}

Univariable and multivariable Cox regression analyses were used to calculate the effect of variables on CSS and OS. The measure of the effect of each variable on CSS and OS is presented as the hazard ratio (HR) and was used to identify independent risk factors. Based on the multivariable Cox regression analyses, two applied nomograms incorporating clinicopathological parameters into the TNM staging system were formulated. The total points in each case of the two survival groups were calculated using the established nomograms, after which Cox regression analysis of the whole cohort was performed using the total points as a parameter. Patients were divided into low- and high-risk groups based on the nomogram risk score and using the median risk score as the cut-off point.

\section{The concordance index (C-index), receiver operating} characteristic (ROC) and decision curve analysis (DCA)

The distinguishing ability of the nomogram was evaluated by the $\mathrm{C}$-index and $\mathrm{ROC}$ curve analysis. The $\mathrm{C}$-index was defined as the ratio of all patient pairs predicted to be consistent with the results. The 1-, 3-, and 5-year ROC curves were used to appraise the nomogram's predictive ability over time. DCA was recently proposed as a fresh method of evaluating predictive models and can be used to visualize the clinical consequences of a treatment method [17]; thus, DCA was carried out to compare the latent profit of the prognostic nomogram in this study.

\section{Risk stratification based on the novel nomogram}

To verify the independent discriminatory ability of the nomogram, this research regrouped all patients into high-, moderate-, and low-risk groups according to the total risk scores. Survival curves for different risk groups were generated using the Kaplan-Meier method and were differentiated using the log-rank test. 
Table 1 Patient characteristics and 1-, 3-, and 5-year CSS and OS rates

\begin{tabular}{|c|c|c|c|c|c|c|c|c|}
\hline \multirow[t]{2}{*}{ Characteristics } & \multirow[t]{2}{*}{$\mathrm{N}$} & \multirow[t]{2}{*}{$\%$} & \multicolumn{3}{|l|}{ CSS } & \multicolumn{3}{|l|}{ os } \\
\hline & & & 1-year (\%) & 3-year (\%) & 5-year (\%) & 1-year (\%) & 3-year (\%) & 5 -year (\%) \\
\hline \multicolumn{9}{|l|}{ Gender } \\
\hline Female & 17,427 & 50.6 & 94.5 & 87.1 & 82.3 & 91.7 & 81.0 & 72.6 \\
\hline Male & 17,005 & 49.4 & 95.5 & 88.5 & 83.1 & 92.0 & 81.4 & 72.0 \\
\hline \multicolumn{9}{|l|}{ Race } \\
\hline White & 26,839 & 78.0 & 94.9 & 88.1 & 83.5 & 91.6 & 81.2 & 72.6 \\
\hline Other $^{\mathrm{a}}$ & 7593 & 22.0 & 95.0 & 87.1 & 82.4 & 92.1 & 81.4 & 71.9 \\
\hline \multicolumn{9}{|l|}{ Year of diagnosis } \\
\hline 2010-2012 & 16,262 & 47.2 & 94.8 & 87.5 & 82.6 & 91.6 & 80.8 & 72.0 \\
\hline 2013-2015 & 18,170 & 52.8 & 95.2 & 87.9 & 84.5 & 92.0 & 81.6 & 76.8 \\
\hline \multicolumn{9}{|l|}{ Age at diagnosis } \\
\hline$<60$ & 10,602 & 30.8 & 98.3 & 92.8 & 87.7 & 97.6 & 91.1 & 85.0 \\
\hline$\geq 60$ & 23,830 & 69.2 & 93.5 & 85.5 & 80.5 & 89.2 & 76.9 & 66.8 \\
\hline \multicolumn{9}{|l|}{ Tumor site } \\
\hline Right & 19,807 & 57.5 & 94.3 & 86.5 & 82.0 & 90.8 & 78.9 & 69.9 \\
\hline Left & 14,625 & 42.5 & 95.9 & 89.5 & 83.8 & 93.2 & 84.3 & 75.6 \\
\hline \multicolumn{9}{|c|}{ Histological subtype } \\
\hline$A D$ & 31,239 & 90.7 & 95.2 & 88.3 & 83.3 & 92.1 & 81.9 & 73.0 \\
\hline MAD & 2903 & 8.4 & 94.2 & 84.8 & 80.0 & 90.4 & 76.6 & 68.0 \\
\hline SRCC & 290 & 0.9 & 78.2 & 58.5 & 51.9 & 74.4 & 52.7 & 44.8 \\
\hline \multicolumn{9}{|l|}{ Pathologic grade } \\
\hline Grade I & 2585 & 7.5 & 97.1 & 92.3 & 89.0 & 94.3 & 85.9 & 78.3 \\
\hline Grade II & 25,438 & 73.9 & 96.0 & 89.6 & 84.6 & 92.9 & 83.1 & 74.2 \\
\hline Grade III & 5374 & 15.6 & 90.5 & 79.4 & 73.7 & 87.1 & 72.9 & 63.3 \\
\hline Grade IV & 1035 & 3.0 & 87.7 & 74.1 & 68.3 & 84.0 & 67.4 & 58.3 \\
\hline \multicolumn{9}{|l|}{ Tstage } \\
\hline $\mathrm{T} 1$ & 3295 & 9.6 & 99.0 & 97.8 & 96.5 & 96.5 & 92.3 & 86.6 \\
\hline $\mathrm{T} 2$ & 5901 & 17.1 & 97.8 & 96.0 & 93.6 & 94.8 & 88.7 & 81.2 \\
\hline T3 & 20,390 & 59.2 & 95.5 & 88.1 & 82.9 & 92.3 & 81.4 & 72.4 \\
\hline $\mathrm{T} 4 \mathrm{a}$ & 3122 & 9.1 & 88.4 & 70.7 & 60.0 & 84.4 & 64.6 & 51.4 \\
\hline $\mathrm{T} 4 \mathrm{~b}$ & 1724 & 5.0 & 84.0 & 66.6 & 56.7 & 80.7 & 61.4 & 50.8 \\
\hline \multicolumn{9}{|l|}{ N stage } \\
\hline No & 20,991 & 61.0 & 96.9 & 93.2 & 90.1 & 93.7 & 85.9 & 78.0 \\
\hline N1 & 9124 & 26.5 & 93.9 & 83.8 & 76.8 & 90.8 & 78.2 & 68.1 \\
\hline N2 & 4317 & 12.5 & 87.8 & 69.7 & 59.6 & 84.9 & 64.7 & 53.4 \\
\hline \multicolumn{9}{|l|}{ Chemotherapy } \\
\hline No & 23,106 & 67.1 & 94.0 & 88.2 & 84.5 & 89.8 & 79.6 & 70.9 \\
\hline Yes & 11,326 & 32.9 & 97.0 & 87.0 & 79.5 & 96.0 & 84.3 & 75.2 \\
\hline \multicolumn{9}{|l|}{ LNH } \\
\hline$<12$ & 3562 & 10.3 & 91.9 & 82.6 & 77.3 & 87.2 & 73.8 & 64.1 \\
\hline$\geq 12$ & 30,870 & 89.7 & 95.3 & 88.4 & 83.4 & 92.3 & 82.1 & 73.3 \\
\hline \multicolumn{9}{|l|}{ LODDS stage } \\
\hline LODDS 1 & 21,981 & 63.8 & 96.9 & 92.9 & 89.7 & 93.6 & 85.6 & 77.7 \\
\hline LODDS 2 & 11,376 & 33.0 & 93.1 & 81.4 & 73.4 & 90.2 & 76.0 & 65.3 \\
\hline LODDS 3 & 1009 & 2.9 & 78.9 & 54.2 & 44.7 & 75.5 & 49.0 & 39.3 \\
\hline LODDS 4 & 66 & 0.3 & 46.1 & 16.8 & 12.0 & 43.2 & 15.8 & 11.3 \\
\hline \multicolumn{9}{|l|}{ Tumor size } \\
\hline$<4$ & 13,757 & 40.0 & 96.9 & 91.6 & 87.4 & 94.0 & 85.2 & 76.6 \\
\hline$\geq 4$ & 20,675 & 60.0 & 93.7 & 85.2 & 79.6 & 90.3 & 78.5 & 69.4 \\
\hline
\end{tabular}


Table 1 (continued)

\begin{tabular}{|c|c|c|c|c|c|c|c|c|}
\hline \multirow[t]{2}{*}{ Characteristics } & \multirow[t]{2}{*}{$\mathbf{N}$} & \multirow[t]{2}{*}{$\%$} & \multicolumn{3}{|l|}{ CSS } & \multicolumn{3}{|l|}{ os } \\
\hline & & & 1-year (\%) & 3-year (\%) & 5-year (\%) & 1-year (\%) & 3-year (\%) & 5-year (\%) \\
\hline \multicolumn{9}{|l|}{ CEA } \\
\hline Negative & 22,289 & 64.7 & 96.6 & 91.4 & 87.5 & 94.0 & 85.7 & 77.9 \\
\hline Positive & 12,143 & 35.3 & 92.0 & 80.9 & 73.7 & 87.8 & 73.0 & 62.0 \\
\hline \multicolumn{9}{|l|}{ Tumor deposit } \\
\hline Negative & 32,106 & 93.2 & 95.3 & 88.8 & 84.0 & 92.2 & 82.1 & 73.3 \\
\hline Positive & 2326 & 6.8 & 90.3 & 72.8 & 63.2 & 86.8 & 68.1 & 56.6 \\
\hline \multicolumn{9}{|l|}{ Marriage status } \\
\hline Married & 19,319 & 56.1 & 96.4 & 90.4 & 85.7 & 94.0 & 85.4 & 77.8 \\
\hline Single & 5576 & 16.2 & 95.2 & 86.4 & 80.8 & 92.1 & 79.9 & 70.8 \\
\hline Separated/Divorced & 3769 & 10.9 & 95.0 & 87.1 & 81.5 & 92.0 & 80.9 & 71.7 \\
\hline Widowed & 5768 & 16.8 & 89.9 & 80.3 & 75.2 & 84.2 & 68.7 & 56.2 \\
\hline \multicolumn{9}{|l|}{ TNM stage } \\
\hline । & 7554 & 21.9 & 98.4 & 97.3 & 95.6 & 95.6 & 90.3 & 83.6 \\
\hline$\|$ & 13,437 & 39.0 & 96.1 & 90.9 & 87.0 & 92.6 & 83.5 & 74.9 \\
\hline III & 13,441 & 39.1 & 92.0 & 79.3 & 71.3 & 88.9 & 73.9 & 63.4 \\
\hline
\end{tabular}

CSS, cause-specific survival, OS overall survival, $A D$ adenocarcinoma, MAD mucinous adenocarcinoma, SRCC signet ring cell carcinoma, $L N H$ lymph nodes harvested, LODDS log of odds between the number of positive lymph node and the number of negative lymph node, CEA carcinoembryonic antigen, TNM tumor-nodemetastasis

a Includes Black, Native American, Asian, Pacific Islander and Unknown

\section{Statistical analyses}

R software (version 3.6.0, http://www.r-project.org) was used for all statistical analyses. The R statistical packages "rms", "survival", "Hmisc", "MASS", and "survivalROC" were used to calculate the C-index, plot the calibration and ROC curves, build the nomogram, and draw KaplanMeier curves, while the package "rmda" was used to draw the DCA curves. All statistical tests were 2-sided, and $\mathrm{p}$ values $<0.05$ were considered statistically significant.

\section{Results}

\section{Patients' clinical characteristics and survival outcomes}

Data on a total of 34,432 patients with stage I-III colon cancer were retrospectively collected from the SEER database. The patients' clinicopathological characteristics and 1-, 3-, and 5-year CSS and OS rates are listed in Table 1.

In the whole group, most patients were White $(26,839$; $78 \%)$ and older than 60 years $(23,830 ; 69.2 \%)$, had the adenocarcinoma histological type $(31,239 ; 90.7 \%)$, moderately differentiated tumors (25,438; 73.9\%), LNH $\geq 12$ (30,870; 89.7\%), and LODDS stage $1(21,981 ; 63.8 \%)$ and were CEA negative $(22,289 ; 64.7 \%)$ and tumor deposit negative $(32,106 ; 93.2 \%)$. Moreover, $67.1 \%$ of patients across the entire study population did not undergo chemotherapy. TNM stage I, II, and III tumors accounted for $21.9 \%, 39.0 \%$, and $39.1 \%$ of all cases, respectively. The 1-, 3 -, and 5-year CSS rates were $95.0 \%, 87.8 \%$, and $82.7 \%$ for all patients, respectively, with a mean follow-up time of 72.7 months. The 1-, 3-, and 5-year OS rates were 91.8\%, $81.2 \%$, and $72.3 \%$ for all patients, respectively, with a mean follow-up time of 66.4 months.

\section{Independent prognostic factors in stage I-III colon cancer patients}

According to the results based on the univariate Cox regression analysis, 13 variables, namely, sex, age at diagnosis, primary tumor site, histological type, pathological grade, adjuvant chemotherapy, LNH, LODDS stage, tumor size, CEA level, marital status, $\mathrm{T}$ stage, and $\mathrm{N}$ stage, were associated with CSS and OS (Tables 2, 3). In the multivariate Cox regression analysis, twelve parameters, namely, age at diagnosis, primary tumor site, histological type, pathological grade, adjuvant chemotherapy, LNH, LODDS stage, tumor size, CEA level, marital status, $\mathrm{T}$ stage, and $\mathrm{N}$ stage, were defined as independent prognostic factors predicting the CSS of stage I-III colon cancer patients (Table 2). All thirteen comparable variables (i.e., sex, age at diagnosis, primary tumor site, histological type, pathological grade, adjuvant chemotherapy, LNH, LODDS stage, tumor size, CEA level, marital status, $\mathrm{T}$ stage, and $\mathrm{N}$ stage) were defined as independent prognostic factors predicting the OS of stage I-III colon cancer patients (Table 3). 
Table 2 Univariable and multivariable Cox regression model analyses of cause-specific survival in nomogram cohort

\begin{tabular}{|c|c|c|c|c|c|c|}
\hline \multirow[t]{2}{*}{ Variable } & \multicolumn{3}{|c|}{ Univariable analysis } & \multicolumn{3}{|c|}{ Multivariable analysis } \\
\hline & HR & $95 \% \mathrm{Cl}$ & P-value & HR & $95 \% \mathrm{Cl}$ & P-value \\
\hline Gender & & & 0.002 & & & 0.066 \\
\hline Female & 1 & & & 1 & & \\
\hline Male & 0.909 & $0.857-0.965$ & & 1.058 & $0.965-1.054$ & \\
\hline Race & & & 0.985 & & & \\
\hline White & 1 & & & & & \\
\hline Other $^{a}$ & 1.001 & $0.907-1.105$ & & & & \\
\hline Year of diagnosis & & & 0.445 & & & \\
\hline 2010-2012 & 1 & & & & & \\
\hline 2013-2015 & 0.976 & $0.915-1.040$ & & & & \\
\hline Age at diagnosis & & & $<0.001$ & & & $<0.001$ \\
\hline$<60$ & 1 & & & 1 & & \\
\hline$\geq 60$ & 1.913 & $1.781-2.056$ & & 1.718 & $1.591-1.856$ & \\
\hline Tumor site & & & $<0.001$ & & & 0.003 \\
\hline Right & 1 & & & 1 & & \\
\hline Left & 0.825 & $0.778-0.875$ & & 0.912 & $0.857-0.970$ & \\
\hline Histological subtype & & & $<0.001$ & & & 0.001 \\
\hline$A D$ & 1 & & & 1 & & \\
\hline MAD & 1.251 & $1.135-1.378$ & $<0.001$ & 0.983 & $0.891-1.085$ & 0.738 \\
\hline SRCC & 4.042 & $3.368-4.851$ & $<0.001$ & 1.444 & $1.195-1.746$ & $<0.001$ \\
\hline Pathological grade & & & $<0.001$ & & & $<0.001$ \\
\hline Grade I & 1 & & & 1 & & \\
\hline Grade II & 1.447 & $1.259-1.664$ & $<0.001$ & 1.080 & $0.939-1.243$ & 0.282 \\
\hline Grade III & 2.867 & 2.477-3.319 & $<0.001$ & 1.350 & $1.162-1.568$ & $<0.001$ \\
\hline Grade IV & 3.704 & $3.091-4.439$ & $<0.001$ & 1.650 & $1.372-1.984$ & $<0.001$ \\
\hline T stage & & & $<0.001$ & & & $<0.001$ \\
\hline $\mathrm{T} 1$ & 1 & & & 1 & & \\
\hline $\mathrm{T} 2$ & 2.022 & $1.590-2.573$ & $<0.001$ & 1.741 & $1.366-2.218$ & $<0.001$ \\
\hline T3 & 5.497 & $4.429-6.822$ & $<0.001$ & 3.579 & $2.864-4.472$ & $<0.001$ \\
\hline T4a & 14.594 & $11.686-18.226$ & $<0.001$ & 7.283 & $5.775-9.186$ & $<0.001$ \\
\hline $\mathrm{T} 4 \mathrm{~b}$ & 17.479 & $13.929-21.933$ & $<0.001$ & 9.477 & $7.467-12.029$ & $<0.001$ \\
\hline N stage & & & $<0.001$ & & & $<0.001$ \\
\hline No & 1 & & & 1 & & \\
\hline N1 & 2.418 & $2.257-2.591$ & $<0.001$ & 2.090 & $1.774-2.461$ & $<0.001$ \\
\hline N2 & 4.679 & $4.437-5.125$ & $<0.001$ & 3.220 & $2.678-3.872$ & $<0.001$ \\
\hline Chemotherapy & & & $<0.001$ & & & $<0.001$ \\
\hline No & 1 & & & 1 & & \\
\hline Yes & 1.142 & $1.076-1.213$ & & 0.498 & $0.465-0.534$ & \\
\hline LNH & & & $<0.001$ & & & $<0.001$ \\
\hline$<12$ & 1 & & & 1 & & \\
\hline$\geq 12$ & 0.669 & $0.617-0.726$ & & 0.582 & $0.535-0.634$ & \\
\hline LODDS stage & & & $<0.001$ & & & $<0.001$ \\
\hline LODDS 1 & 1 & & & 1 & & \\
\hline LODDS 2 & 2.689 & $2.528-2.861$ & $<0.001$ & 1.290 & $1.097-1.517$ & 0.002 \\
\hline LODDS 3 & 7.359 & $6.64-8.156$ & $<0.001$ & 2.005 & $1.647-2.442$ & $<0.001$ \\
\hline LODDS 4 & 21.948 & $16.814-28.649$ & $<0.001$ & 4.274 & $3.109-5.876$ & $<0.001$ \\
\hline Tumor size & & & $<0.001$ & & & 0.038 \\
\hline$<4$ & 1 & & & 1 & & \\
\hline$\geq 4$ & 1.781 & $1.671-1.899$ & & 1.075 & $1.004-1.152$ & \\
\hline
\end{tabular}


Table 2 (continued)

\begin{tabular}{|c|c|c|c|c|c|c|}
\hline \multirow[t]{2}{*}{ Variable } & \multicolumn{3}{|c|}{ Univariable analysis } & \multicolumn{3}{|c|}{ Multivariable analysis } \\
\hline & HR & $95 \% \mathrm{Cl}$ & P-value & HR & $95 \% \mathrm{Cl}$ & P-value \\
\hline CEA & & & $<0.001$ & & & $<0.001$ \\
\hline Negative & 1 & & & 1 & & \\
\hline Positive & 2.292 & $2.163-2.429$ & & 1.575 & $1.484-1.671$ & \\
\hline Marriage status & & & $<0.001$ & & & $<0.001$ \\
\hline Married & 1 & & & 1 & & \\
\hline Single & 1.323 & $1.199-1.459$ & $<0.001$ & 1.197 & $1.085-1.321$ & $<0.001$ \\
\hline Separated/Divorced & 1.397 & $1.285-1.519$ & $<0.001$ & 1.298 & $1.193-1.493$ & $<0.001$ \\
\hline Widowed & 2.084 & $1.937-2.243$ & $<0.001$ & 1.470 & $1.362-1.587$ & $<0.001$ \\
\hline
\end{tabular}

HR hazard ratio, $C l$ confidence interval, $A D$ adenocarcinoma, MAD mucinous adenocarcinoma, SRCC signet ring cell carcinoma, $L N H$ lymph nodes harvested, $L O D D S$ log of odds between the number of positive lymph node and the number of negative lymph node, CEA carcinoembryonic antigen, $T N M$ tumor-node-metastasis

a Includes Black, Native American, Asian, Pacific Islander and Unknown

\section{Construction and validation of the prognostic prediction nomogram}

Considering the results of the multivariable Cox regression analysis for CSS and OS, all of the significant variables were used to create the nomogram for CSS and OS. The prognostic nomogram for 1-, 3-, and 5-year CSS is shown in Fig. 2. The prognostic nomogram for 1-, 3-, and 5-year OS is shown in Fig. 3. By summing the scores associated with each variable and projecting total scores to the bottom scale, the probabilities can be estimated for 1-, 3-, and 5-year CSS and OS.

$\mathrm{C}$-index values and ROC curves are ordinarily used to evaluate the discriminatory power of a nomogram. The $\mathrm{C}$-indexes for the prediction of CSS and OS were 0.78 (95\% CI $0.77-0.80)$ and 0.74 (95\% confidence interval (CI) 0.73-0.75), respectively. To confirm that the nomogram had higher efficacy in predicting the prognosis of stage I-III colon cancer patients than TNM stage, time-dependent ROC analyses at 1, 3, and 5 years were conducted. The 1-, 3-, and 5-year AUC values of the nomogram for the prediction of CSS were $0.81,0.807$, and 0.787 , respectively, compared with $0.646,0.680$, and 0.683 , respectively, for the AUC values of TNM stage (Fig. 4a-c). In addition, the 1-, 3-, and 5-year AUC values of the nomogram for the prediction of OS were 0.782, 0.76 , and 0.741 , respectively, compared with $0.592,0.613$, and 0.606, respectively, for the AUC values of TNM stage (Fig. $4 \mathrm{~d}-\mathrm{f}$ ). In addition, calibration curves for the nomogram showed no deviations from the reference line, which indicating a high degree of credibility (Fig. 5a-f).

The clinically and statistically significant prognostic performance of the nomogram based on the entire group of patients and risk scores was validated by a stratified analysis, which suggested that the nomogram could be used to clinically and statistically predict the prognosis of patients with stage II (Fig. 6a, b), and stage II-III colon cancer with or without adjuvant chemotherapy (Fig. 6e-h).

\section{Clinical value of the nomogram}

DCA is a novel method used to evaluate alternative prognostic strategies and has advantages over the AUC. DCA curves for the novel nomogram and TNM stage are presented in Fig. 7. Compared with the TNM staging system, the DCA of the nomogram has higher net benefits, indicating that it has better clinical application value than TNM stage.

\section{Prognostic nomogram for risk stratification}

By regrouping all patients in the CSS and OS cohorts into three subgroups based on the total scores, the cut-off values were defined, and each group represents a distinct prognosis. The Kaplan-Meier survival curves were subsequently delineated and are shown in Fig. 8. In the CSS cohort, Group 1 (low-risk group) had the highest 5-year CSS rate of $95.0 \%$, followed by Group 2 (moderate-risk group; 88.6\%) and Group 3 (high-risk group 64.0\%). In the OS cohort, Group 1 (low-risk group) had the highest 5 -year OS rate of $89.1 \%$, followed by Group 2 (moderaterisk group 76.8\%) and Group 3 (high-risk group 51.5\%). A significant statistical distinction in survival outcomes was observed between the three groups.

\section{Discussion}

Through this study, a nomogram merging clinicopathological parameters with the TNM staging system was built to assess the definite 1-, 3-, and 5-year CSS and OS probabilities of stage I-III colon cancer patients. The behavior of the nomogram (i.e., discrimination and calibration) was verified. From the perspective of clinical influence, the nomogram had a wide range of 
Table 3 Univariable and multivariable Cox regression model analyses of overall survival in nomogram cohort

\begin{tabular}{|c|c|c|c|c|c|c|}
\hline \multirow[t]{2}{*}{ Variable } & \multicolumn{3}{|c|}{ Univariable analysis } & \multicolumn{3}{|c|}{ Multivariable analysis } \\
\hline & HR & $95 \% \mathrm{Cl}$ & P-value & HR & $95 \% \mathrm{Cl}$ & P-value \\
\hline Gender & & & 0.017 & & & 0.001 \\
\hline Female & 1 & & & 1 & & \\
\hline Male & 1.005 & $1.002-1.036$ & & 1.248 & $1.190-1.309$ & \\
\hline Race & & & 0.097 & & & \\
\hline White & 1 & & & & & \\
\hline Other ${ }^{a}$ & 0.970 & $0.935-1.006$ & & & & \\
\hline Year of diagnosis & & & 0.082 & & & \\
\hline 2010-2012 & 1 & & & & & \\
\hline 2013-2015 & 0.957 & $0.910-1.006$ & & & & \\
\hline Age at diagnosis & & & $<0.001$ & & & $<0.001$ \\
\hline$<60$ & 1 & & & 1 & & \\
\hline$\geq 60$ & 2.724 & $2.560-2.899$ & & 2.228 & $2.086-2.379$ & \\
\hline Tumor site & & & $<0.001$ & & & $<0.001$ \\
\hline Right & 1 & & & 1 & & \\
\hline Left & 0.753 & $0.719-0.789$ & & 0.865 & $0.825-0.908$ & \\
\hline Histological subtype & & & $<0.001$ & & & 0.001 \\
\hline$A D$ & 1 & & & 1 & & \\
\hline MAD & 1.260 & $1.170-1.358$ & $<0.001$ & 1.024 & $0.949-1.104$ & 0.540 \\
\hline SRCC & 2.947 & $2.500-3.474$ & $<0.001$ & 1.403 & $1.184-1.663$ & $<0.001$ \\
\hline Pathologic grade & & & $<0.001$ & & & $<0.001$ \\
\hline Grade I & 1 & & & 1 & & \\
\hline Grade II & 1.199 & $1.090-1.320$ & $<0.001$ & 1.029 & $0.934-1.134$ & 0.557 \\
\hline Grade III & 1.923 & $1.734-2.134$ & $<0.001$ & 1.206 & $1.083-1.342$ & 0.001 \\
\hline Grade IV & 2.371 & $2.064-2.724$ & $<0.001$ & 1.418 & $1.231-1.634$ & $<0.001$ \\
\hline T stage & & & $<0.001$ & & & $<0.001$ \\
\hline $\mathrm{T} 1$ & 1 & & & 1 & & \\
\hline $\mathrm{T} 2$ & 1.462 & $1.292-1.654$ & $<0.001$ & 1.317 & $1.162-1.493$ & $<0.001$ \\
\hline T3 & 2.268 & $2.034-2.528$ & $<0.001$ & 1.769 & $1.576-1.987$ & $<0.001$ \\
\hline $\mathrm{T} 4 \mathrm{a}$ & 4.671 & $4.146-5.262$ & $<0.001$ & 3.114 & $2.737-3.543$ & $<0.001$ \\
\hline $\mathrm{T} 4 \mathrm{~b}$ & 5.110 & $4.498-5.806$ & $<0.001$ & 3.634 & $3.163-4.175$ & $<0.001$ \\
\hline N stage & & & $<0.001$ & & & $<0.001$ \\
\hline No & 1 & & & 1 & & \\
\hline N1 & 1.533 & $1.456-1.615$ & $<0.001$ & 1.646 & $1.444-1.876$ & $<0.001$ \\
\hline $\mathrm{N} 2$ & 2.557 & $2.413-2.709$ & $<0.001$ & 2.364 & $2.035-2.746$ & $<0.001$ \\
\hline Chemotherapy & & & $<0.001$ & & & $<0.001$ \\
\hline No & 1 & & & 1 & & \\
\hline Yes & 0.733 & $0.697-0.771$ & & 0.429 & $0.404-0.455$ & \\
\hline LNH & & & $<0.001$ & & & $<0.001$ \\
\hline$<12$ & 1 & & & 1 & & \\
\hline$\geq 12$ & 0.674 & $0.633-0.717$ & & 0.621 & $0.581-0.663$ & \\
\hline LODDS stage & & & $<0.001$ & & & $<0.001$ \\
\hline LODDS 1 & 1 & & & 1 & & \\
\hline LODDS 2 & 1.674 & $1.598-1.754$ & $<0.001$ & 1.247 & $1.093-1.423$ & 0.001 \\
\hline LODDS 3 & 3.941 & $3.602-4.312$ & $<0.001$ & 1.853 & $1.570-2.188$ & $<0.001$ \\
\hline LODDS 4 & 10.562 & $8.166-13.662$ & $<0.001$ & 3.592 & $2.674-4.825$ & $<0.001$ \\
\hline Tumor size & & & $<0.001$ & & & 0.048 \\
\hline$<4$ & 1 & & & 1 & & \\
\hline$\geq 4$ & 1.446 & $1.379-1.517$ & & 1.050 & $1.004-1.102$ & \\
\hline
\end{tabular}


Table 3 (continued)

\begin{tabular}{|c|c|c|c|c|c|c|}
\hline \multirow[t]{2}{*}{ Variable } & \multicolumn{3}{|c|}{ Univariable analysis } & \multicolumn{3}{|c|}{ Multivariable analysis } \\
\hline & HR & $95 \% \mathrm{Cl}$ & P-value & HR & $95 \% \mathrm{Cl}$ & P-value \\
\hline CEA & & & $<0.001$ & & & $<0.001$ \\
\hline Negative & 1 & & & 1 & & \\
\hline Positive & 1.943 & $1.858-2.032$ & & 1.515 & $1.446-1.587$ & \\
\hline Marriage status & & & $<0.001$ & & & $<0.001$ \\
\hline Married & 1 & & & 1 & & \\
\hline Single & 1.318 & $1.220-1.423$ & $<0.001$ & 1.266 & $1.171-1.367$ & $<0.001$ \\
\hline Separated/divorced & 1.366 & $1.279-1.460$ & $<0.001$ & 1.394 & $1.304-1.491$ & $<0.001$ \\
\hline Widowed & 2.375 & $2.248-2.510$ & $<0.001$ & 1.756 & $1.654-1.865$ & $<0.001$ \\
\hline
\end{tabular}

HR hazard ratio, $C I$ confidence interval, $A D$ adenocarcinoma, MAD mucinous adenocarcinoma, SRCC signet ring cell carcinoma, $L N H$ lymph nodes harvested, $L O D D S$ log of odds between the number of positive lymph node and the number of negative lymph node, CEA carcinoembryonic antigen, TNM tumor-node-metastasis

a Includes Native American, Asian, Pacific Islander and Unknown

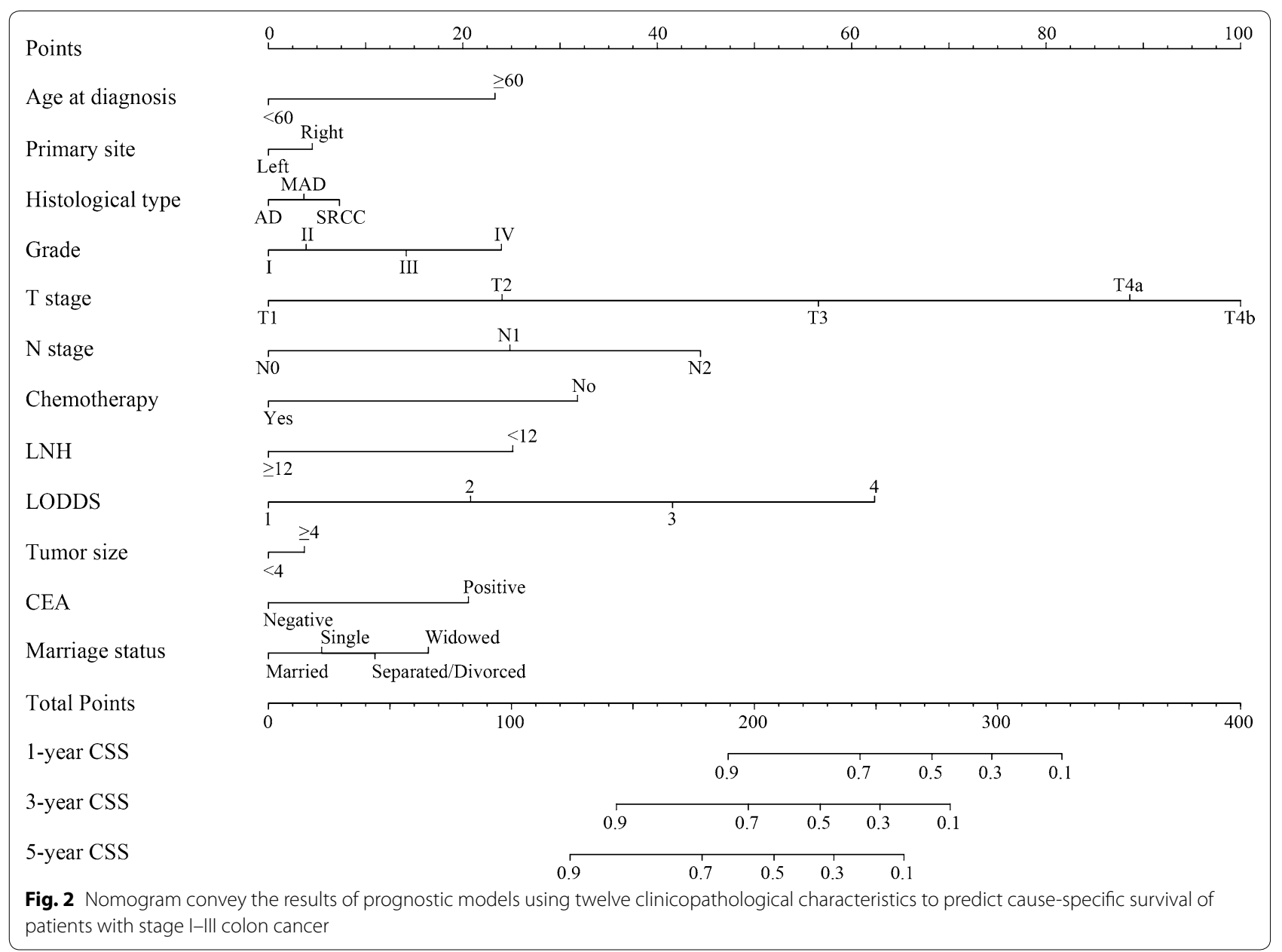




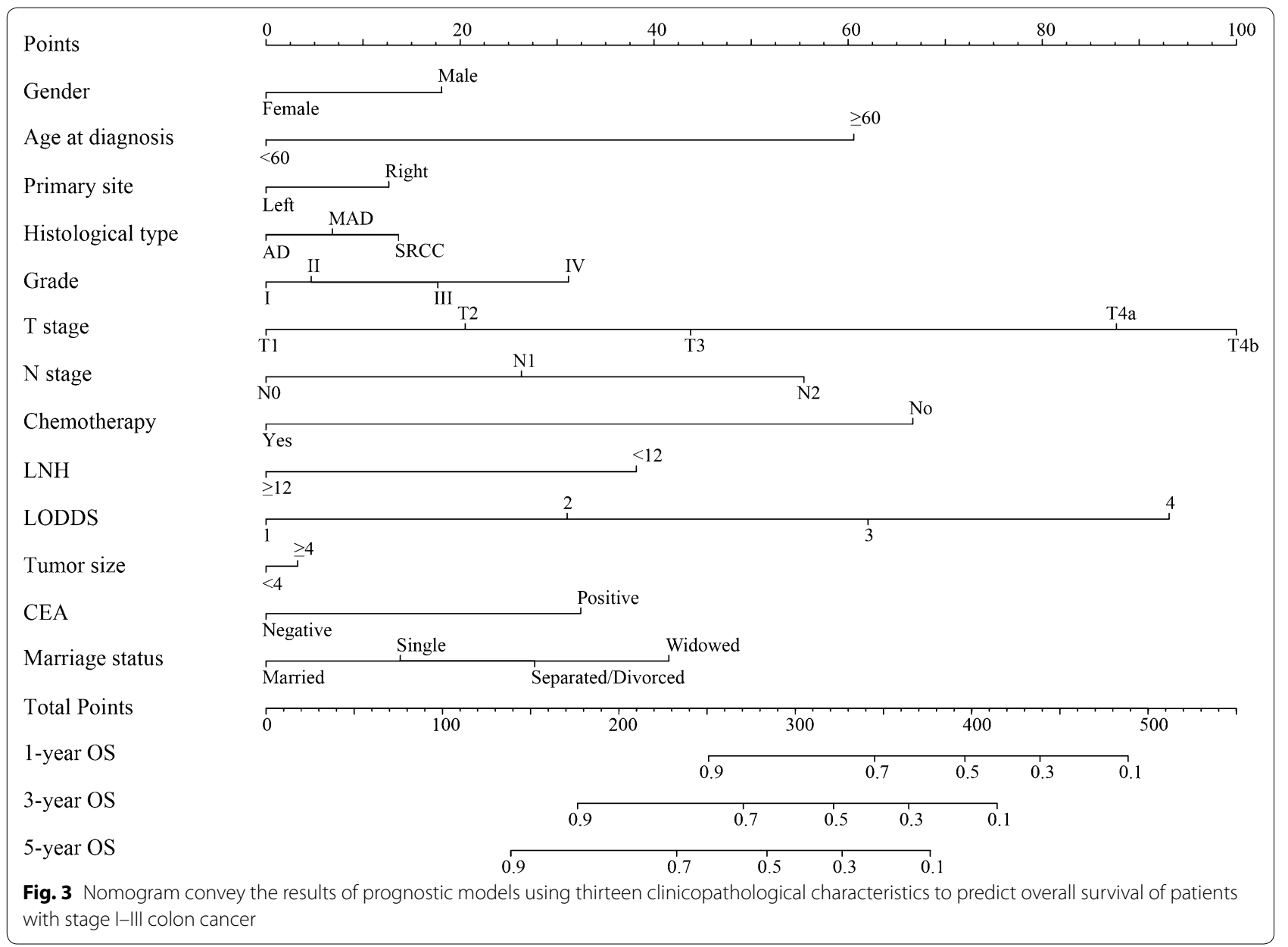

threshold probabilities. From the perspective of ROC curve analysis and DCA, the nomogram showed better predictive accuracy and prognostic value in stage I-III colon cancer compared to the current TNM staging system. Moreover, the nomogram was competent to divide patients with stage I-III colon cancer into low-, moderate-, and high-risk groups, which indicates that the nomogram can be utilized as a conventional equipment in predicting the prognosis of stage I-III colon cancer.

In the present study, it was found that the number of young individuals diagnosed with colon cancer has increased. Previous research has revealed that age is an independent prognostic factor of stage I-III colon cancer patients, with a younger age indicating more pronounced outcomes [6]. In addition, a considerable prognostic factor certified by this study was CEA, which is a wellestablished biomarker for colon cancer recommended by both the American Society of Clinical Oncology (ASCO) and the European Group on Tumor Markers (EGTM) [18-20]. Preoperative CEA levels were used to predict prognosis, and routine CEA monitoring during the postoperative follow-up was used to monitor local relapse and distant metastases after colon cancer surgery. As this nomogram showed, stage I-III colon cancer patients with high CEA levels tended to have significantly poor CSS and $\mathrm{OS}$ rates. In addition, left-sided colon cancers (LCCs) and right-sided colon cancers (RCCs) are thought to have different embryological origins [21]. Various differences, such as anatomical structure, function, morphological characteristics, and histochemical reactions, exist between the two. Patients with LCC have a significantly better prognosis than those with RCC in terms of OS, which was indicated by this research. In addition, tumor size [5] was validated as an independent factor for OS in patients with colorectal adenocarcinoma of infiltrative and ulcerative types in a previous study. This research suggested that large tumors led to a poor prognosis. 

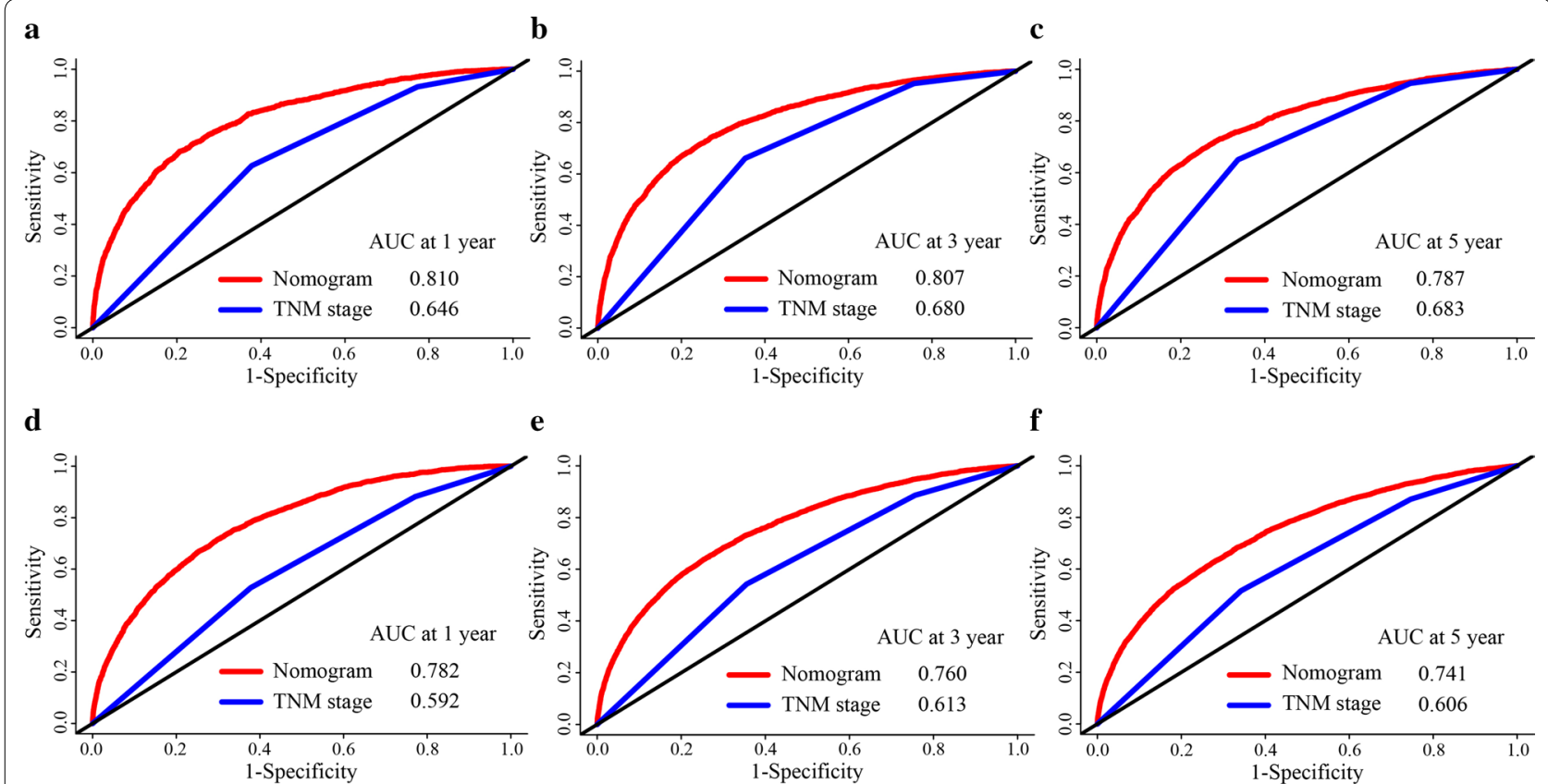

Fig. 4 a AUC values of ROC predicted 1-year cause-specific survival rates of Nomogram and TNM stage. b AUC values of ROC predicted 3-year cause-specific survival rates of Nomogram and TNM stage. c AUC values of ROC predicted 5-year cause-specific survival rates of Nomogram and TNM stage. d AUC values of ROC predicted 1-year overall survival rates of Nomogram and TNM stage. e AUC values of ROC predicted 3-year overall survival rates of Nomogram and TNM stage. f AUC values of ROC predicted 5-year overall survival rates of Nomogram and TNM stage
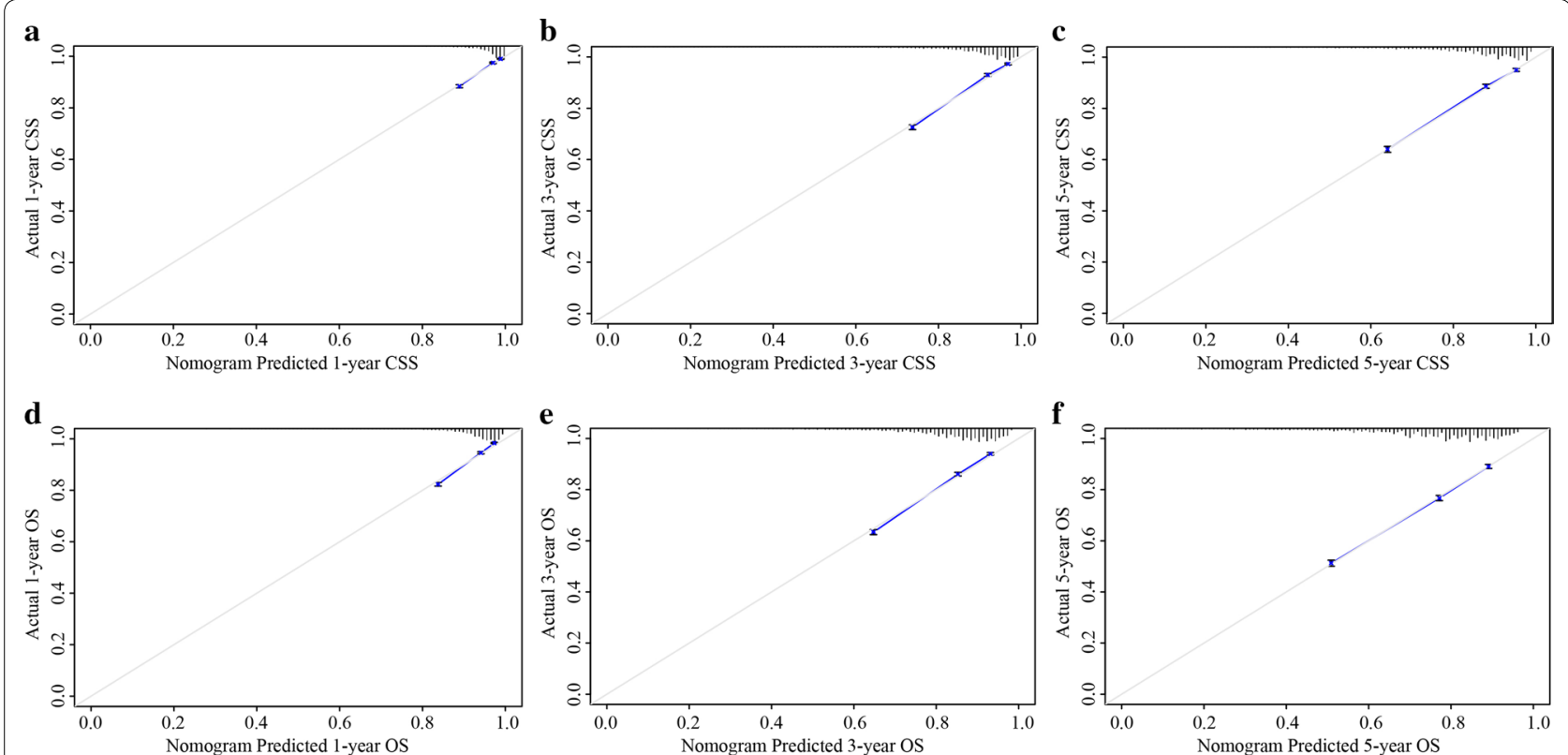

Fig. 5 a The calibration curve for predicting patients' cause-specific survival at 1-year. b The calibration curve for predicting patients' cause-specific survival at 3-year. c The calibration curve for predicting patients' cause-specific survival at 5-year. $\mathbf{d}$ The calibration curve for predicting patients' overall survival at 1-year. e The calibration curve for predicting patients' overall survival at 3-year. f The calibration curve for predicting patients' overall survival at 5 -year 
(See figure on next page.)

Fig. 6 a Kaplan-Meier estimated cause-specific survival in patients with TNM stage II colon cancer stratified by the nomogram risk score. b Kaplan-Meier estimated overall survival in patients with TNM stage II colon cancer stratified by the nomogram risk score. c Kaplan-Meier estimated cause-specific survival in patients with TNM stage III colon cancer stratified by the nomogram risk score. $\mathbf{d}$ Kaplan-Meier estimated overall survival in patients with TNM stage III colon cancer stratified by the nomogram risk score. e Kaplan-Meier estimated cause-specific survival in stage II-III colon cancer patients without chemotherapy stratified by the nomogram risk score. $\mathbf{f}$ Kaplan-Meier estimated overall survival in stage II-III colon cancer patients without chemotherapy stratified by the nomogram risk score. $\mathbf{g}$ Kaplan-Meier estimated cause-specific survival in stage II-III colon cancer patients with chemotherapy stratified by the nomogram risk score. $\mathbf{h}$ Kaplan-Meier estimated overall survival in stage II-III colon cancer patients with chemotherapy stratified by the nomogram risk score

Whether adjuvant chemotherapy is suitable for stage I-III colon cancer remains controversial. According to the NCCN guidelines, it is recommended that patients with stage II colon cancers with risk factors and stage III colon cancers accept adjuvant chemotherapy [22, 23]. In this study, histological differentiation, grade, right colon, LNH less than 12, LODDS, tumor size, marital status, $\mathrm{T}$ stage, and $\mathrm{N}$ stage were identified as independent risk factors for stage I-III colon cancer [14]. Histological differentiation was identified as an important feature to evaluate the benefit of adjuvant chemotherapy in a previous study [24]. This nomogram proved that low histological differentiation was associated with a poor prognosis. Low histological grade was considered among the adverse histopathological factors associated with an unfavorable clinical course of colon cancer. A previous study demonstrated that tumor location was associated with prognosis in colon cancer patients [21]. Furthermore, the appropriate staging of colon cancer requires at least 12 lymph nodes to be sampled, as recommended by the NCCN guidelines. Relevant research indicated that stage I-III colon cancer patients with LNH less than 12 tended to have shorter CSS and OS than those with LNH more than 12, which corroborated the results of this nomogram [25].

Some scholars have trusted that the LODDS is a more accurate method for predicting the prognosis of patients with colon cancer after an operation than the $\mathrm{N}$ stage. The LODDS was defined as follows: $\log ($ (number of positive lymph nodes +0.05)/(number of negative nodes +0.05$)$ ). The LODDS range in this research was -3.256 to 2.858 . The LODDS system was divided into four levels to determine the LODDS status: LODDS1 (LODDS $\leq-1.5)$, LODDS2 $(-1.5 \leq$ LODDS $<0)$, LODDS3 $(0 \leq \mathrm{LODDS}<1.5)$, and LODDS4 (LODDS $\geq 1.5)[26,27]$.
This nomogram showed that a high LODDS status was related to poor survival outcomes.

Marital status is another independent prognostic factor for survival in colon cancer. Previous research showed that being married was associated with better outcomes of colon cancer patients, but unmarried colon cancer patients, including single, separated, divorced, and widowed patients, were at a greater risk of mortality [15], which was reproduced in this research. Our nomogram shows that separated, divorced, and widowed patients were associated with a greater risk of mortality.

However, this study still had some limitations. First, treatment information except for surgery was not available in the SEER database and was thus not incorporated into our analysis. Second, the SEER database is devoid of variables such as detailed histological information, mode of presentation, and ECOG prognostic scores and lacks 90\% of biomarker expression states (e.g., RAS, BRAF, PIK3CA and genes involved in DNA mismatch repair, which have been proven to predict survival). Last, this study did not contain any external validation cohort. Additional prospective data and the incorporation of other factors are encouraged to improve this model.

\section{Conclusion}

In conclusion, we established and validated a nomogram for predicting CSS and OS probabilities in stage I-III colon cancer patients. The simple nomogram had sufficient discriminatory and calibration capability in addition to exceptional clinical effectiveness and could be an easy-to-use tool for clinicians to promote a personalized postoperative prognostic assessment and to identify treatment strategies for patients with stage I-III colon cancer. 
A TNM stage II

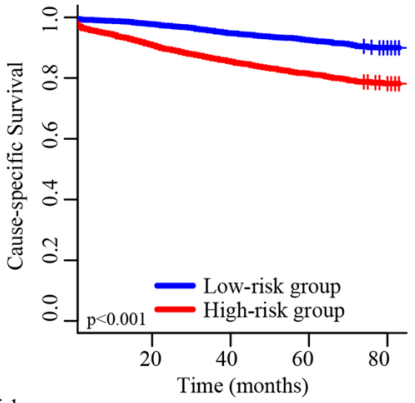

No. At Risk

$\begin{array}{llllll}\text { Low-risk group } & 6718 & 5385 & 3270 & 1611 & 225\end{array}$ $\begin{array}{llllll}\text { High-risk group } & 6719 & 4768 & 2803 & 1275 & 178\end{array}$

C TNM stage III

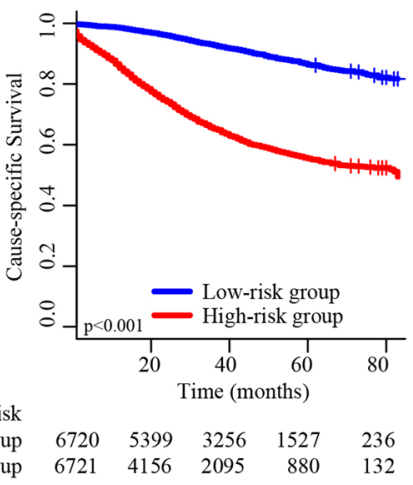

E Chemotherapy: No

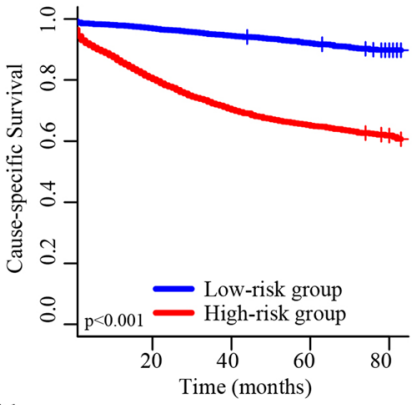

No. At Risk $\begin{array}{llllll}\text { Low-risk group } & 7802 & 6094 & 3731 & 1766 & 247\end{array}$ $\begin{array}{llllll}\text { High-risk group } & 7802 & 4775 & 2595 & 1159 & 178\end{array}$

$$
\text { G Chemotherapy: Yes }
$$

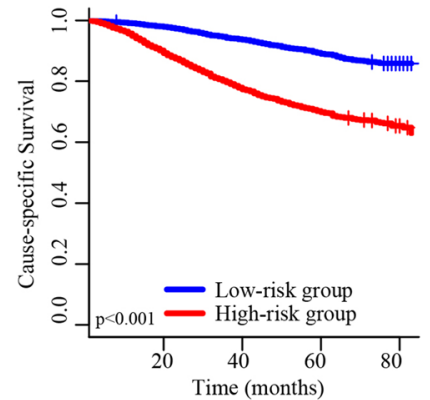

No. At Risk

$\begin{array}{llllll}\text { Low-risk group } & 5637 & 4614 & 2791 & 1353 & 194\end{array}$ $\begin{array}{llllll}\text { High-risk group } & 5637 & 4225 & 2307 & 1015 & 152\end{array}$
B TNM stage II

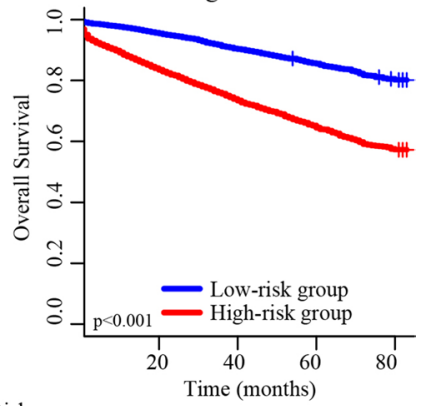

No. At Risk

$\begin{array}{llllll}\text { Low-risk group } & 6718 & 5379 & 3259 & 1600 & 221\end{array}$ $\begin{array}{llllll}\text { High-risk group } & 6719 & 4774 & 2814 & 1286 & 182\end{array}$ D TNM stage III

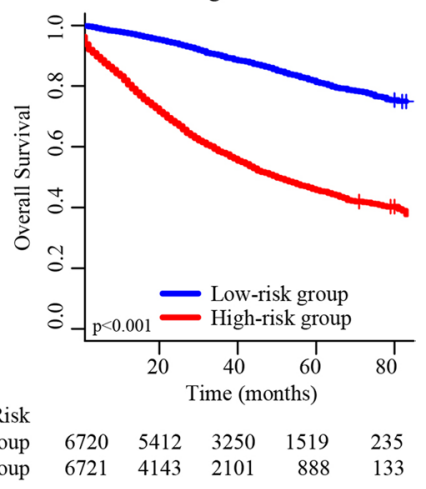

F Chemotherapy: No

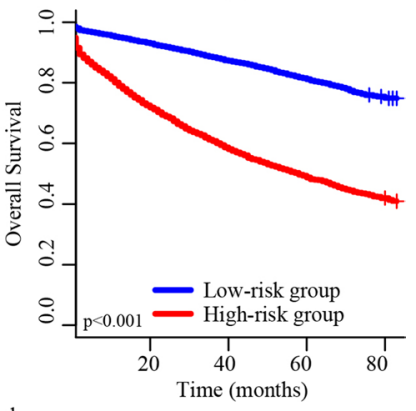

No. At Risk $\begin{array}{llllll}\text { Low-risk group } & 7802 & 6071 & 3703 & 1754 & 246\end{array}$ $\begin{array}{llllll}\text { High-risk group } & 7802 & 4798 & 2623 & 1171 & 179\end{array}$ H Chemotherapy: Yes

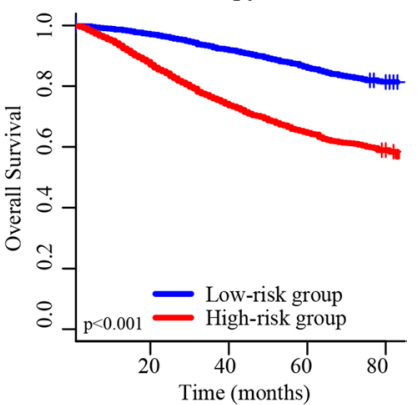

No. At Risk

$\begin{array}{llllll}\text { Low-risk group } & 5637 & 4621 & 2802 & 1337 & 197\end{array}$ $\begin{array}{llllll}\text { High-risk group } & 5637 & 4218 & 2296 & 1031 & 149\end{array}$ 


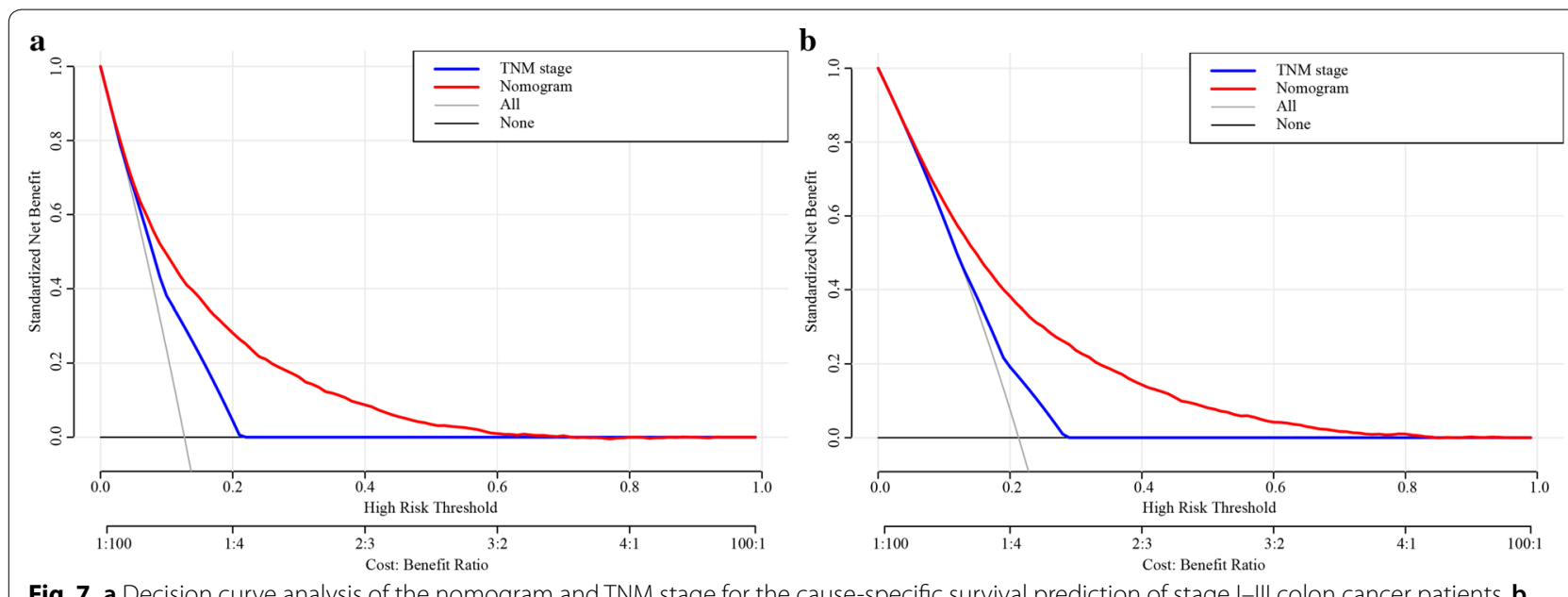

Fig. 7 a Decision curve analysis of the nomogram and TNM stage for the cause-specific survival prediction of stage I-III colon cancer patients. $\mathbf{b}$ Decision curve analysis of the nomogram and TNM stage for the overall survival prediction of stage I-III colon cancer patients
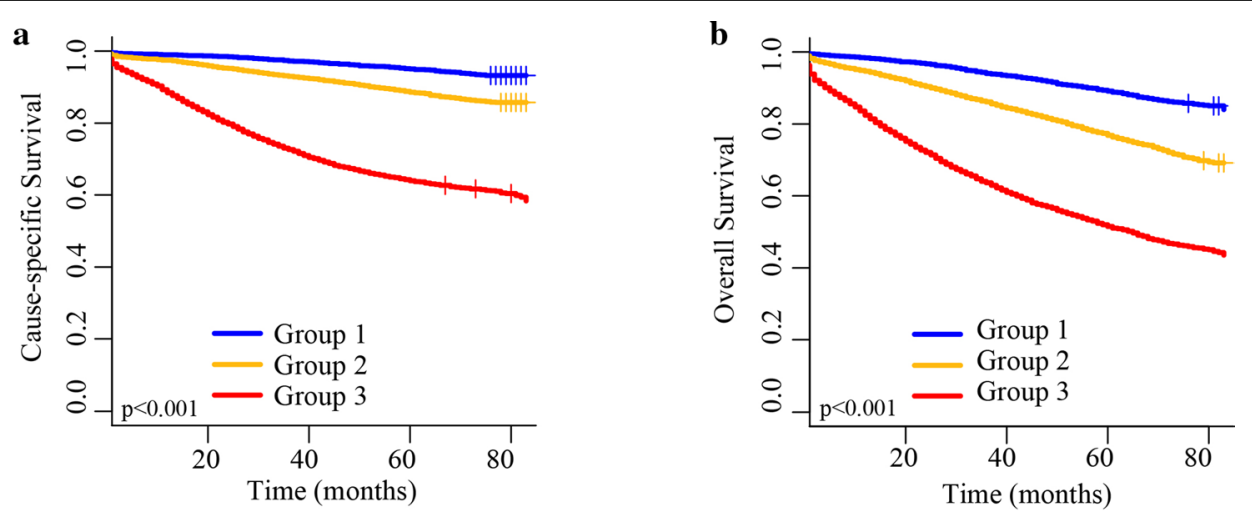

$\begin{array}{rlllll}\text { No. At Risk } & & & & & \\ \text { Group 1 } & 11477 & 9233 & 5720 & 2865 & 419 \\ \text { Group 2 } & 11478 & 8955 & 5422 & 2527 & 376 \\ \text { Group 3 } & 11477 & 7498 & 4004 & 1758 & 267\end{array}$

$\begin{array}{rlllll}\text { No. At Risk } & & & & & \\ \text { Group 1 } & 11477 & 9280 & 5748 & 2827 & 419 \\ \text { Group 2 } & 11478 & 9001 & 5430 & 2585 & 382 \\ \text { Group 3 } & 11477 & 7405 & 3968 & 1738 & 261\end{array}$

Fig. 8 a Cause-specific survival in the subgroups according to a tertiles of the total score. $\mathbf{b}$ Overall survival in the subgroups according to a tertiles of the total score

\section{Acknowledgements}

The authors would like to thank the Surveillance, Epidemiology, and End Results (SEER) database for the support.

\section{Authors' contributions}

ZZ and SBM had the idea for this study. WXD, WQX and LYH supervised the acquisition of the data. ZZ and SBM undertook the statistical analysis. QGL, RJW, and LZ provided statistical advice. All authors contributed to interpretation of the results. LZ, SJC and GXC wrote the article and other authors contributed to the content. All authors read and approved the final manuscript.

\section{Funding}

This study was supported by the National Key R\&D Program of China (Nos. 2016YFC0905300 and 2016YFC0905301), the Grant of Science and Technology Commission of Shanghai Municipality (No. 16401970502), the Grant of National Natural Science Foundation of China (No. 81572351), the Shanghai Shenkang Program (No. SHDC12014206), the National Science Foundation of
China (No. 81702353) and Shanghai Municipal Natural Science Foundation (17ZR1406400). The funders had no role in the study design, data collection and analysis, decision to publish, or preparation of the manuscript.

\section{Availability of data and materials}

The dataset used during the study are available from the corresponding author on a reasonable request.

\section{Ethics approval and consent to participate}

The Ethical Committee and Institutional Review Board of the Fudan University Shanghai Cancer Center reviewed and approved this study protocol.

\section{Consent for publication}

Not applicable.

\section{Competing interests}

The authors declare that they have no competing interests. 


\section{Author details}

${ }^{1}$ Department of Colorectal Surgery, Fudan University Shanghai Cancer Center, 270 Dong'an Road, Shanghai 200032, China. ${ }^{2}$ Department of Oncology, Shanghai Medical College, Fudan University, 270 Dong'an Road, Shanghai 200032, China. ${ }^{3}$ Department of Cancer Institute, Fudan University Shanghai Cancer Center, Fudan University, Shanghai 200032, China. ${ }^{4}$ School of Foreign Languages and Cultures, Chongqing University, Chongqing 401331, China.

Received: 24 September 2019 Accepted: 17 December 2019 Published online: 27 December 2019

\section{References}

1. Chen W, Zheng R, Baade PD, Zhang S, Zeng H, Bray F, Jemal A, Yu XQ, He J. Cancer statistics in China, 2015. Cancer J Clin. 2016;66(2):115-32.

2. Torre LA, Bray F, Siegel RL, Ferlay J, Lortet-Tieulent J, Jemal A. Global cancer statistics, 2012. Cancer J Clin. 2015;65(2):87-108.

3. Siegel RL, Miller KD. Cancer statistics. Cancer J Clin. 2019;69(1):7-34.

4. O'Connell JB, Maggard MA, Kong CY. Colon cancer survival rates with the new American Joint Committee on Cancer sixth edition staging. J Natl Cancer Inst. 2004:96(19):1420-5.

5. Dai W, Li Y, Meng X, Cai S, Li Q, Cai G. Does tumor size have its prognostic role in colorectal cancer? Re-evaluating its value in colorectal adenocarcinoma with different macroscopic growth pattern. Int J Surg. 2017;45:105-12.

6. Abasse Kassim S, Tang W, Abbas M, Wu S, Meng Q, Zhang C, Li X, Chen R. Clinicopathologic and epidemiological characteristics of prognostic factors in post-surgical survival of colorectal cancer patients in Jiangsu Province, China. Cancer Epidemiol. 2019;62:101565.

7. Gryfe R, Kim H, Hsieh ET, Aronson MD, Holowaty EJ, Bull SB, Redston M, Gallinger S. Tumor microsatellite instability and clinical outcome in young patients with colorectal cancer. N Engl J Med. 2000;342(2):69-77.

8. Watanabe T, Wu TT, Catalano PJ, Ueki T, Satriano R, Haller DG, Benson AB 3rd, Hamilton SR. Molecular predictors of survival after adjuvant chemotherapy for colon cancer. N Engl J Med. 2001;344(16):1196-206.

9. Dalchau R, Kirkley J, Fabre JW. Monoclonal antibody to a human braingranulocyte-T lymphocyte antigen probably homologous to the W 3/13 antigen of the rat. Eur J Immunol. 1980;10(10):745-9.

10. Ciardiello F, Tortora G. EGFR antagonists in cancer treatment. N Engl J Med. 2008:358(11):1160-74

11. Haseba M, Hidaka S, Tsuji T, Yano H, Komatsu H, Sawai T, Yasutake T, Nakagoe T, Tagawa Y, Ayabe H. Detection of p53 gene mutations by nonisotopic RNase cleavage assay as a predictor of poor prognosis in colorectal cancers. Dig Dis Sci. 2003;48(10):1984-9.

12. Liu YJ, Yan PS, Li J, Jia JF. Expression and significance of CD44s, CD44v6, and nm23 mRNA in human cancer. World J Gastroenterol. 2005:11(42):6601-6.

13. lasonos A, Schrag D, Raj GV, Panageas KS. How to build and interpret a nomogram for cancer prognosis. J Clin Oncol. 2008;26(8):1364-70.

14. Chen SH, Wan QS, Zhou D, Wang T, Hu J, He YT, Yuan HL, Wang YQ, Zhang $\mathrm{KH}$. A simple-to-use nomogram for predicting the survival of early hepatocellular carcinoma patients. Front Oncol. 2019;9:584.
15. Wang X, Cao W, Zheng C, Hu W, Liu C. Marital status and survival in patients with rectal cancer: an analysis of the Surveillance, Epidemiology and End Results (SEER) database. Cancer Epidemiol. 2018;54:119-24.

16. Zhang G, Wu Y, Zhang J, Fang Z, Liu Z, Xu Z, Fan Y. Nomograms for predicting long-term overall survival and disease-specific survival of patients with clear cell renal cell carcinoma. Oncol Targets Ther. 2018;11:5535-44.

17. Vickers AJ, Elkin EB. Decision curve analysis: a novel method for evaluating prediction models. Med Decis Making. 2006;26(6):565-74.

18. Shibutani M, Maeda K, Nagahara H, Ohtani H, Sakurai K, Toyokawa T, Kubo N, Tanaka H, Muguruma K, Ohira M, et al. Significance of CEA and CA19-9 combination as a prognostic indicator and for recurrence monitoring in patients with stage II colorectal cancer. Anticancer Res. 2014;34(7):3753-8.

19. Locker GY, Hamilton S, Harris J, Jessup JM, Kemeny N, Macdonald JS, Somerfield MR, Hayes DF, Bast RC Jr. Asco: aSCO 2006 update of recommendations for the use of tumor markers in gastrointestinal cancer. J Clin Oncol. 2006;24(33):5313-27.

20. Duffy MJ, van Dalen A, Haglund C, Hansson L, Klapdor R, Lamerz R, Nilsson O, Sturgeon C, Topolcan O. Clinical utility of biochemical markers in colorectal cancer: European Group on Tumour Markers (EGTM) guidelines. Eur J Cancer. 2003;39(6):718-27.

21. Yahagi M, Okabayashi K, Hasegawa H, Tsuruta M, Kitagawa Y. The worse prognosis of right-sided compared with left-sided colon cancers: a systematic review and meta-analysis. J Gastrointest Surg. 2016;20(3):648-55.

22. Benson AB 3rd, Venook AP, Al-Hawary MM, Cederquist L, Chen YJ, Ciombor KK, Cohen S, Cooper HS, Deming D, Engstrom PF, et al. Rectal cancer, Version 2.2018, NCCN clinical practice guidelines in oncology. JNCCN. 2018;16(7):874-901.

23. Benson AB 3rd, Venook AP, Cederquist L, Chan E, Chen YJ, Cooper HS, Deming D, Engstrom PF, Enzinger PC, Fichera A, et al. Colon cancer, version 12017, NCCN clinical practice guidelines in oncology. J Natl Compr Canc Netw. 2017;15(3):370-98.

24. Barresi V, Reggiani Bonetti L, leni A, Caruso RA, Tuccari G. Histological grading in colorectal cancer: new insights and perspectives. Histol Histopathol. 2015;30(9):1059-67.

25. Li Destri G, Barchitta M, Pesce A, Latteri S, Bosco D, Di Cataldo A, Agodi A, Puleo S. Predictive value of the number of harvested lymph nodes and cut-off for lymph node ratio in the prognosis of stage II and III colorectal cancer patients. J Invest Surg. 2019;32(1):1-7.

26. Ramacciato G, Nigri G, Petrucciani N, Pinna AD, Ravaioli M, Jovine $E$, Minni F, Grazi GL, Chirletti P, Tisone G, et al. Prognostic role of nodal ratio, LODDS, pN in patients with pancreatic cancer with venous involvement. BMC Surg. 2017;17(1):109.

27. Fortea-Sanchis C, Martinez-Ramos D, Escrig-Sos J. The lymph node status as a prognostic factor in colon cancer: comparative population study of classifications using the logarithm of the ratio between metastatic and nonmetastatic nodes (LODDS) versus the pN-TNM classification and ganglion ratio systems. BMC Cancer. 2018;18(1):1208.

\section{Publisher's Note}

Springer Nature remains neutral with regard to jurisdictional claims in published maps and institutional affiliations. 